\title{
Smarter inspection will improve food safety in Canada
}

\author{
Richard A. Holley PhD
}

Previously published at www.cmaj.ca

$\mathrm{P}$ roblems in the Canadian food safety system are deeply rooted in the multijurisdictional systems that govern and monitor the health of Canadians and regulate the quality and safety of food. Although government recognizes that the prime responsibility for producing safe food rests with industry, it has been slow to learn several important lessons. Safety must be built into foods, not inspected into them. Smarter inspection, not more inspection, will improve safety. It is important to understand the risks in both food and pathogens. Over the past several decades, we have borrowed illness surveillance data from other countries to assess risk, ${ }^{1}$ but demographics, ethnicity, eating patterns and diet are specific to each country. In addition, changes in climate affect the ability of pathogens to influence the safety of food. Multijurisdictional fragmentation of both food inspection and food-borne illness surveillance are obstacles to safety that can be overcome with determination and commitment. However, adequate surveillance of foodborne illness will require investment.

\section{Surveillance of food-borne illness}

Canadian surveys of self-reported acute gastroenteritis estimate that there are about 11 million cases of food-borne illness yearly, with an estimated mean annual cost of $\$ 10899^{2,3}$ More accurate data would be desirable, but there is no national surveillance program for food-borne illness in this country. At present, Canada's national reporting system for enteric disease comprises two elements: the National Notifiable Infectious Disease Reporting System, which accumulates case information across the country, and the National Enteric Surveillance Program, which documents laboratory results. Under-reporting of illnesses is a generic deficiency in such systems, but this is made worse in Canada by inconsistent handling of the data. Case results in five provinces and territories are aggregated before they are entered in the infectious disease reporting system, and the data from water, food, humans and animals in the enteric surveillance program are not segregated. Collaboration is needed within government to elicit uniform and complete data while respecting patient confidentiality.

To characterize the extent of under-reporting of acute gastroenteritis in Canada, the National Studies on Gastrointestinal Illness were established. The self-reported data show that for every case captured by the national surveillance system, there are between 10 and 50 cases of acute gastroenteritis caused by verotoxigenic Escherichia coli, Salmonella and Campylobacter. ${ }^{2}$ Data from the National Studies on Gastrointestinal Illness will be incorporated into those being generated by the World Health Organization (WHO) as it aims to estimate the global burden of food-borne illness by $2012 ., 5$ The WHO initiative will produce

\section{Key points}

- The Canadian food safety system is reactive, and its development has not kept pace with new knowledge used by other countries to protect consumers.

- Food-borne illness surveillance is a passive patchwork of regional systems that feed poor quality data on illness outbreaks into the database on notifiable infectious diseases.

- These surveillance systems ignore the large sporadic illness component, which is more useful in discovering the major sources of illness and developing policy to manage them.

- Food operations are now inspected at three government levels to different standards; operation of the multigovernment agency interface for both illness surveillance and food inspection should be seamless.

- We must address changes in pathogens (identity or antimicrobial resistance) and foods as they evolve through insightful policy based on sound Canadian data.

an atlas of the burden of global food-borne disease and generate tools that will allow individual countries to capture domestic data. Burden will be characterized in terms of disability-adjusted life years and will enable comparison of the impact of disease based on severity, frequency and mortality rates. Although many developed countries collect data on food vehicles and pathogens, the WHO program will also include toxins and parasites.

Even with maturation of the WHO program, the Canadian Food Safety System (operated by three levels of government) needs to be proactive and manage prioritized risks. Canada needs to collect information on food vehicles and agents responsible for food-borne illness. Countries in the European Union, the United States and Australia have established such surveillance, enabling contemporary assessment of risk management activities, ${ }^{6}$ which is not possible in Canada. Data from outbreaks of food-borne illness can contribute to effective risk management, provided one recognizes that these cases represent a smaller proportion of food-borne illness than those that occur sporadically and are not part of an outbreak. This is particularly true of Campylobacter, which is believed to cause the largest number of cases of gastroenteritis in Canada. ${ }^{7}$ For example, in 2007 in Australia there were four recorded outbreaks of campylobacteriosis that involved 20 people, but there were almost 17000 cases for which authorities were notified. ${ }^{8}$ Thus, comprehensive surveillance programs will include investigations of both outbreaks and sporadic cases, which will

From the Department of Food Science, Faculty of Agricultural and Food Sciences, University of Manitoba, Winnipeg, Man.

CMAJ 2010. DOI:10.1503/cmaj.090517 
require coordination as well as timely and transparent exchange of information at local, provincial-territorial and federal levels. When coupled with a uniform group of notifiable diseases across the country, regional differences might be detectable.

Establishing the surveillance program for food- and waterborne illness - C-EnterNet, a multipartner initiative facilitated by the Public Health Agency of Canada - is a step in the right direction. At a first sentinel site in Ontario, the program monitors the health of a half-million people. With its renewed mandate last year and plans to establish a second site (of five in the future) in Alberta this year, it is hoped that attribution data for food can be collected and used to characterize risk and inform food safety policy.

\section{Food inspection issues}

Canada, unlike the US, has one national food inspection authority, the Canadian Food Inspection Agency, which is responsible for administering the Consumer Packaging and Labelling Act as it relates to food. It also has de facto responsibility for all food inspection, but in reality it shares this responsibility with the provinces, territories and municipal governments. Although the agency has arm's length independence, it reports to the Minister of Agriculture and Agri-Food Canada. This is considered by some to represent a client-related conflict of interest because the minister's mandate includes industry and trade promotion. (This author has not seen any indication of a conflict of interest, either in his experience as a manager of an agency-inspected facility or as an independent third party.)

The Canadian Food Inspection Agency is responsible for registering facilities that process foods (as identified in the Canadian Agricultural Products Act as well as the Meat and Fish Inspection acts) that are traded interprovincially or are exported or imported. Standards governing all aspects of processing and handling, including facility registration, operation and inspection, are consistent with those of international trading partners. However, when traded within provincialterritorial borders, the same products require only regional approval and must comply with a second tier of often less stringent regulations administered by provincial agriculture, environment or health departments. Food service organizations (e.g., restaurants, hotels, hospitals) operate within a third tier of regulations established by municipal governments (usually health departments). Provinces and local governments have their own inspection staff and training programs, which increase the likelihood of heterogeneity in program delivery. The Canadian Food Inspection Agency suggests that roughly $60 \%$ of the Canadian food dollar is used to purchase food that is subject to inspection by the agency. ${ }^{9}$ This is of no concern if the frequency of inspection is based on risks in food safety. Of greater concern are the differences in standards applied by government at the three levels. The systems were developed in response to regional needs (i.e., growth); however, the inconsistency must be resolved in light of Canada's being a signatory to the World Trade Organization's Agreement on Sanitary and Phytosanitary Measures which allows importation of foods that have been produced to the least stringent domestic (provincial-local) standards.

\section{Inspection and investigation of outbreaks of food-borne illness}

The diverse mandates for inspection influence the delegation of responsibility for investigating outbreaks of food-borne illness, thereby increasing the chance of inconsistent data recovery. In parallel with the national listeriosis outbreak in 2008 investigated by the Canadian Food Inspection Agency were two outbreaks (87 cases and one death linked to salmonellosis, and 22 cases and one death linked to listeriosis) from cheese manufactured in two plants that had been inspected by the province (second tier). ${ }^{10}$ Both outbreaks were investigated by Quebec's ministries of health, and agriculture, fisheries and food. Seize and destroy orders by the latter ministry superseded voluntary recalls of the cheese by the companies involved. All three outbreaks were contained within four months after detection. Against all reasonable odds, a fourth outbreak, caused by Escherichia coli $\mathrm{O} 157: \mathrm{H7}$, occurred later that year that was linked to food from a Harvey's fast-food restaurant in Ontario. ${ }^{11}$ This investigation initially became the responsibility of an Ontario county health unit (third tier).

Canada's size, regional differences in population density and varying availability of infrastructure complicate attempts to implement and administer uniform food inspection and outbreak surveillance programs. Regions with high population density have more mature inspection and surveillance systems but use inadequate methods for capturing data. A difficult question is whether all provinces protect Canadians equally. The answer is no if one believes that regulations and inspection guarantee food safety; the answer is yes if one considers the integrity of industry.

The rigour of food inspection and surveillance for foodborne illness are linked. In the absence of an inspection policy based on risk (which is key to effective management of risk), inspection will continue to focus on requirements for compliance with label formats, fill weights and terminology for ingredients, all of which can be easily measured against guidelines. Inspection of this type has its place, but it contributes little to overall safety. Smart inspection with proactive detection of deficiencies in the safety of foods is more elusive because it requires insightful analysis of system operations. Such analysis is less likely to garner attention because it requires more sophisticated inspection, more training and more appraisal time.

The primary responsibility for manufacturing safe food rests with industry. Smart, risk-based inspection to ensure that the system is operating within guidelines is highly complementary. Although such inspection may involve periodic testing of the end product, performance targets must be used with caution. Because pathogens usually occur with low frequency, the statistical power of product sampling is inadequate to provide confidence in the overall safety of foods subject to such testing. Another danger is that a shift in regulatory emphasis toward reliance on performance testing will draw industry resources away from improving systems and monitoring activities. Where this has happened in the US and elsewhere, it can be interpreted to mean that regulatory agencies do not believe that proactive systems, such as Hazard Analysis Critical Control Point programs, work. Industry's response has been predictable. 


\section{Understanding new hazards}

Sustainability of agriculture is only possible when nutrients are recycled. However, reprocessing of animal protein waste as an ingredient in animal feed and the use of manure as fertilizer can result in pathogenic contamination further along the food chain.

Recent events worldwide have shown that we do not consistently control the agents that cause food-borne illness. Directly or indirectly, domestic and wild animals are the source of zoonotic pathogens, which are often carried asymptomatically and shed by animals. It is generally accepted that zoonotic pathogens can be concentrated in food animals if manure is used improperly. Less recognition is given to the potential for feed contaminated by Salmonella or toxigenic E. coli (25\% to $80 \%$ of feed samples ${ }^{12}$ ) to inoculate food animals. Because of the almost ubiquitous occurrence of these organisms in some animal environments, it is difficult to conclude that eliminating them from feed will have a measurable impact on food safety in the short term. Continuous challenge of animals with contaminated food lengthens the period that animals shed contaminating pathogens. In addition, it now seems that, because of contaminated feed, E.coli O157:H7 can be found in hogs and poultry, where its absence was previously conspicuous. ${ }^{13}$

Because antibiotics are used in animal feed to promote growth, repeated exposure of recycled pathogens to antibiotics may increase the frequency of acquired antibiotic resistance by these organisms.

During the bovine spongiform encephalopathy (mad cow) epidemic, removal of the suspect protein from the ruminant feed supply was expensive but successful. ${ }^{14}$ Yet this disease, when combined with avian influenza, has been responsible for about 300 human deaths worldwide (if one accepts that the prion that causes bovine spongiform encephalopathy also causes the human form of the disease, variant Creutzfeldt-Jakob disease). In stark contrast, and with few headlines, Salmonella and Listeria each kills about 500 people in the US every year. ${ }^{15}$

\section{Steps to food safety in Canada}

1. Government must go beyond interagency memoranda of understanding to develop permanent systems that promote cooperation and sharing of information on surveillance of food-borne illness and investigations of outbreaks.

2. Investment is needed to develop a surveillance program on food-borne illness that will characterize risks related to food and food pathogens in Canada.

3. Data from surveillance must be used to develop inspection policy that is based on risk and is uniform across the country. That policy's main priority must be to validate that approved food safety systems are operated properly.

4. Campylobacteriosis is an inadequately understood anomaly. Campylobacter seems to survive poorly in the environment and is a zoonotic commensal in most poultry and probably beef. Because the organism tends to cause only mild, self-resolving gastroenteritis in humans, it is not usually captured in surveillance data; however, in several countries, including Canada, it is believed to cause the most cases of enteric illness (perhaps 30 cases/100 000 people compared with 17 cases caused by Salmonella/100 000 people $\left.{ }^{7}\right)$. More research is needed to understand this organism, but the magnitude of its impact on human health suggests an immediate and large payback from taking steps to prevent campylobacteriosis caused by food. Experience in Belgium and Iceland suggests that the sale of only frozen poultry (freezing kills Campylobacter) or the irradiation of poultry will reduce food-borne illness by $25 \%$ to $50 \% .^{16,17}$

5. It appears that most cases of food-borne illness are acquired in restaurants and residential homes; therefore, education and training in food handling and preparation must continue to be a high priority.

Competing interests: Richard Holley was a manager of the federally inspected (by the Canadian Food Inspection Agency) dairy plant in the Department of Food Science, University of Manitoba. He is a member of the CFIA Academic Advisory Panel, for which he receives an honorarium.

\section{REFERENCES}

1. Bryan FL, Guzewich JJ, Todd ECD. Surveillance of foodborne disease III. Summary and presentation of data on vehicles and contributory factors; their value and limitations. J Food Prot 1997;60:701-14

2. Thomas MK, Majowicz SE, Pollari F, et al. Burden of acute gastrointestinal illness in Canada, 1999-2007: interim summary of NSAGI activities. Can Commun Dis Rep 2008;34:8-15. Available: www.phac-aspc.gc.ca/publicat/ccdr-rmtc /08vol34/dr-rm3405b-eng.php (accessed 2009 Nov. 26).

3. Majowicz SE, McNab WB, Sockett $P$, et al. Burden and cost of gastroenteritis in a Canadian community. J Food Prot 2006;69:651-9.

4. Hird S, Stein C, Kuchenmuller T, et al. Meeting report: second annual meeting of the World Health Organization initiative to estimate the global burden of foodborne diseases. Int J Food Microbiol 2009;1331:210-2.

5. Senior K. Estimating the global burden of foodborne disease. Lancet Infect Dis 2009;9:80-1.

6. Greig JD, Ravel A. Analysis of foodborne outbreak data reported internationally for source attribution. Int J Food Microbiol 2009;130:77-87.

7. Laboratory surveillance data for enteric pathogens in Canada: 2006 annual summary. Winnipeg (MB): National Microbiology Laboratory, Public Health Agency of Canada; 2007. Available: http://www.nml-lnm.gc.ca/NESP-PNSME/assets /pdf/2006AnnualReport.pdf (accessed 2010 Jan. 13)

8. OzFoodNet. Monitoring the incidence and causes of diseases potentially transmitted by food in Australia: annual report of the OzFoodNet Network, 2007. Commun Dis Intell 2008:32:400-24.

9. Canadian Food Inspection Agency - Food inspection programs. In: Report of the Auditor General of Canada. Ottawa (ON): Office of the Auditor General of Canada; 2000.

10. Galanis E, Shyng S. Listeriosis outbreaks in Canada in 2008. Vancouver (BC): BC Centre for Disease Control, BC Food Protection Association; 2009. Available: www.bcfpa.net/Attachments/Presentations/Listeriosis\%20outbreaks\%20in\%20Canada \%20in\%202008\%20(E\%20Galanis\%20\&\%20S\%20Shyng)\%2019\%20Jan\%202009 .pdf (accessed 2010 Jan 8)

11. North Bay Parry Sound District Health Unit. Investigative summary of the Escherichia coli outbreak associated with a restaurant in North Bay, Ontario: October to November 2008. North Bay (ON): The Unit; 2009. Available: www.healthunit.biz /docs/Ecoli\%20Outbreak/2008\%20NBPSDHU\%20Ecoli\%20Report_June\%202009 Formatted.pdf (accessed 2010 Jan. 8).

12. Sapkota AR, Lefferts LY, McKenzie S, et al. What do we feed to food-production animals? A review of animal feed ingredients and their potential impact on human health. Environ Health Perspect 2007;115:663-70.

13. Doane CA, Pangloli P, Richards HA, et al. Occurrence of Escherichia coli O157:H7 in diverse farm environments. J Food Prot 2007;70:6-10.

14. Hueston W, Bryant CM. Transmissible spongiform encephalopathies. J Food Sci 2005;70:R77-R87.

15. Mead PS, Slutsker L, Dietz V, et al. Food-related illness and death in the United States. Emerg Infect Dis 1999;5:607-25.

16. Stern NJ, Hiett KL, Alfredsson GA, et al. Campylobacter spp. in Icelandic poultry operations and human disease. Epidemiol Infect 2003;130:23-32.

17. Vellinga A, Van Loock F. The dioxin crisis as experiment to determine poultryrelated campylobacter enteritis. Emerg Infect Dis 2002;8:19-22.

Correspondence to: Dr. Richard A. Holley, Department of Food Science, Faculty of Agricultural and Food Sciences, University of Manitoba, Winnipeg MB R3T 2N2; rick_holley@umanitoba.ca 